\title{
Correlation of the Imaging Findings with Bronchoscopic Findings for the Detection of Endobronchial Lesions: A Systematic Review and Meta-Analysis
}

Marousa Kouvela*, Sotirios Kakavas, Christos Karetsos and Evangelos Balis

Department of Pulmonary Medicine, Evangelismos Hospital, Athens, Greece

\begin{abstract}
Background: The purpose of this systematic review was to compare the diagnostic accuracy of axial thoracic $\mathrm{CT}$, other imaging techniques and image reconstruction algorithms with the endoscopic findings of Fiberopptic Bronchoscopy (FOB), in patients with newly detected endobronchial lesions.

Methods: A systematic review of the literature for retrospective and prospective studies was performed. Articles considered included patients with endobronchial stenosis that were subjected to axial Computed Tomography of the chest with or without an image reconstruction technique, and Fiberoptic Bronchoscopy.

Results: 10 studies ( 6 prospective/4 retrospective) that were published in PubMed or CancerLit met the inclusion criteria. A total number of 633 patients were involved in the studies and an additional number of 53 patients were included as controls. All the patients were subjected to Fiberoptic Bronchoscopy (FOB) and imaging of the chest. The meta-analysis showed a high sensitivity for most imaging techniques, comparable with this of Fiberoptic Bronchoscopy, but with a significant Negative Predictive Value.
\end{abstract}

Conclusion: Even though the imaging techniques are a useful, fast and safe modality for the detection of endobronchial lesions, the high negative predictive value raises a concern on their sufficiency for the exclusion of lung cancer on high risk patients.

Keywords: Bronchoscopy; Chest; Computed tomography (CT); Interventional pulmonology; Lung cancer; Endobronchial lesion; Meta-analysis

\section{Introduction}

Lung cancer is one of the leading causes of death worldwide. Furthermore, the incidence of lung cancer remains significantly high and a large number of lung cancer related deaths is expected to occur during the following years $[1,2]$. In early stages, lung cancer presents with a few or no symptoms at all, so the patients delay in seeking medical assistance. As a result, most cases of lung cancer present at an inoperable stage, even at the time of diagnosis [3]. Every patient who is in a high risk group and presents with respiratory symptoms should be investigated for the possibility of lung cancer. Computed Tomography (CT) scan of the chest is a common imaging technique for the detection and characterization of suspected lesions of the lung and offers a plethora of information, such as morphological characteristics of the lesion, staging of the possible disease and prediction of the operability $[4,5]$.

A common problem in clinical practice is high-risk patients presenting with symptoms compatible with lung cancer. The first step in the diagnosis of a suspected lesion is the imaging of the chest and for this purpose chest CT scan is a valuable tool which has demonstrated high sensitivity and specificity rates [6]. Nevertheless, chest CT still has limitations and that is why over the years, various advanced techniques have been developed aiming to a more detailed assessment of the lungs and chest, using 2-D and 3-D reconstruction algorithms $[7,8]$. Moreover, an accurate histological diagnosis has to be obtained for the confirmation of the disease [9]. A useful method for this purpose is Fiberoptic Bronchoscopy (FOB), which usually represents the first choice diagnostic modality for the accurate diagnosis of a suspected lesion [10-12]. However, this method is subject to limitations too, as the sensitivity of bronchoscopic techniques decreases significantly for peripheral lesions and also it remains an invasive method with possible complications and restrictions for the elderly and more disabled patients $[11,12]$.

The purpose of this article is to review the correlations between bronchoscopic findings using Fiberoptic bronchoscopy (FOB) and imaging findings delivered by axial thoracic CT or other imaging techniques and image reconstruction algorithms in patients with mainly malignant endobronchial lesions.

\section{Methodology}

The studies that were included in this review were prospective or retrospective studies concerning the imaging and bronchoscopic characteristics of endobronchial lesions [13-23]. The individuals that were included in the studies were patients of any age with an endobronchial lesion which could be malignant, benign or undiagnosed. The term "endobronchial lesion" was referred to nodules, masses or stenoses of the central airways and the trachea. All the participants were subjected in chest CT imaging and Fiberoptic Bronchoscopy. Moreover, in some cases, a more advanced imaging technique with the usage of reconstruction algorithms of the chest images was studied. The results of these diagnostic interventions were compared with each other

*Corresponding author: Marousa Kouvela, Department of Pulmonary Medicine, Evangelismos Hospital, Athens, Greece, Tel: 00306970882774; E-mail: markouvela@yahoo.gr

Received January 09, 2017; Accepted February 17, 2017; Published February 21, 2017

Citation: Kouvela M, Kakavas S, Karetsos C, Balis E (2017) Correlation of the Imaging Findings with Bronchoscopic Findings for the Detection of Endobronchial Lesions: A Systematic Review and Meta-Analysis. J Pulm Respir Med 6: 395. doi: 10.4172/2161-105X.1000395

Copyright: ( $) 2017$ Kouvela M, et al. This is an open-access article distributed under the terms of the Creative Commons Attribution License, which permits unrestricted use, distribution, and reproduction in any medium, provided the original author and source are credited. 
Citation: Kouvela M, Kakavas S, Karetsos C, Balis E (2017) Correlation of the Imaging Findings with Bronchoscopic Findings for the Detection of Endobronchial Lesions: A Systematic Review and Meta-Analysis. J Pulm Respir Med 6: 395. doi: 10.4172/2161-105X.1000395

Page 2 of 10

and compared with the findings of the bronchoscopic intervention, so that the accuracy of chest CT imaging could be assessed. This review was limited to the comparison of chest CT imaging with bronchoscopy for the detection and characterization of endobronchial lesions. The primary outcome was the detection, description and final diagnosis of the endobronchial lesion.

The search of the literature was performed in PubMed database and CancerLit. The keywords used were "CT" or "imaging" AND "endobronchial lesion" or "endobronchial neoplasm" or "endobronchial tumor" or "lung cancer" AND "bronchoscopy". The search was limited only to papers written in English, but no limit was applied for the publication date. The search of the literature was initiated in August 2014 and terminated in November 2014. One author conducted the search of the literature from titles and abstracts, and selected the most useful papers after analyzing the full text of the retrieved articles, screened the extracted information and assessed the selected articles for the validity of the information provided. The data extraction was performed using a standardized extraction form from the Cochrane collaboration, adjusted according to this study. Extracted data included patient's characteristics (age, gender, symptoms, type of lesion and time between CT and bronchoscopy); study design (prospective, retrospective or unknown); interpretation of the bronchoscopic and imaging findings (blinded or not); and technical information about the imaging and bronchoscopic techniques used in each patient. A second author assessed the quality and diagnostic accuracy of the studies by using the QUADAS-2 tool. The QUADAS-2 tool is a revised tool for the quality assessment of diagnostic accuracy studies, which was developed to improve the only validated quality assessment tool, the original QUADAS tool $[24,25]$. This tool comprises 4 domains for the assessment of risk of bias and applicability of each study. These 4 domains are: 1 . Patient selection 2. Index test 3. Reference standard and 4 . Flow and timing. After this procedure, a number of studies with low quality or applicability score according to those domains of the QUADAS-2 were excluded from the review and the most appropriate studies were selected (Table 1 and Supplement 1).

Two tables were constructed for each study. The first table included the Positive Predictive Value (PPV), the Negative Predictive Value (NPV), the sensitivity and specificity of the diagnostic technique. The second table categorized the results as positive or negative for the detection of endobronchial lesion for each diagnostic technique used in comparison with bronchoscopy, which was used as the reference for the detection of endobronchial lesions.

\section{Statistical analysis}

The presence of heterogeneity was assessed by means of a test on the $\mathrm{Q}$ statistic and calculated the $\mathrm{I}^{2}$ index. If $\mathrm{I}^{2}$ values were more than $50 \%$, we considered these data significantly heterogeneous [1]. We used bivariate models to obtain summary estimates of sensitivity and specificity along with 95\% confidence intervals (95\% CI). Positive likelihood ratio (LR+), negative likelihood ratio (LR-) and diagnostic $\log$ odds ratios (DORs) were derived as functions of these summary estimates. The accuracy was pooled by fitting a summary receiver operating characteristic (SROC) curve and summarizing that curve by means of the area under the curves. The $\mathrm{z}$ test was performed to analyze differences in sensitivity and specificity estimates among 3 tests. All $p$ values reported are two-tailed. Statistical significance was set at 0.05 and analyses were conducted using STATA statistical software (version 11.0) [24-26].

\section{Results}

The research of the literature revealed 495 relevant citations to consider. After reviewing the titles and abstracts, 18 articles met the criteria and were candidates for full text analysis [13-23,27-33]. The articles that were excluded in this first phase of selection were no relevant in the scope of this review. From those selected, 8 were excluded from this study, three papers did not compare the imaging with the bronchoscopic findings, two papers did not use the detection of the lesion as the target point of the study, in one, there was no recording of the imaging findings, in one there was no clear display of the statistical analysis of the results and in another, the selection of the patients included a high risk of bias [27-33] (Table 2). As a result, 10 articles were finally selected and analyzed for our review study [13-23].

From the 10 studies that were included in this review, six were prospective and four retrospective studies, all published in English. All studies were performed in different medical centers in Europe and the USA. A total number of 633 patients with endobronchial lesions were included and in 4 studies, an additional number of 53 patients with no endobronchial findings were included as controls. The mean age of patients was 59.5 years, with a range from 6-89 years. Of those, 454

\begin{tabular}{|c|c|c|c|c|c|c|c|}
\hline \multirow[t]{2}{*}{ Study } & \multicolumn{4}{|c|}{ Risk of Bias } & \multicolumn{3}{|c|}{ Applicability } \\
\hline & $\begin{array}{c}\text { Patient } \\
\text { selection }\end{array}$ & Index test & Reference standard & Flow and timing & Patient selection & Index test & Reference standard \\
\hline Bungay et al. [13] & (;) & & (:) & (;) & (:) & (;) & (;) \\
\hline Ferreti et al. [14] & (:) & & (:) & (:) & (:) & (:) & (:) \\
\hline Lecourtois et al. [15] & (:) & & (:) & (:) & (;) & (:) & (:) \\
\hline Westeinde et al. [16] & (:) & & (:) & (:) & (:) & (:) & (:) \\
\hline Hoppe et al. [17] & (:) & & (:) & (:) & (:) & (;) & (:) \\
\hline Adali et al. [18] & (:) & & (2) & (:) & (2) & (2) & (2) \\
\hline Naidich et al. [19] & (;) & & (:) & (:) & (:) & (:) & (:) \\
\hline Aristizabal et al. [20] & (:) & & (:) & (:) & (:) & (:) & (:) \\
\hline Finkelstein et al. [21] & (;) & & (;) & (:) & (;) & (:) & (:) \\
\hline Koletsis et al. [22] & (:) & & (:) & (:) & (2) & (2) & (2) \\
\hline
\end{tabular}

Table 1: QUADAS-2 tool for the assessment of risk of bias and applicability of the selected studies. 
Citation: Kouvela M, Kakavas S, Karetsos C, Balis E (2017) Correlation of the Imaging Findings with Bronchoscopic Findings for the Detection of Endobronchial Lesions: A Systematic Review and Meta-Analysis. J Pulm Respir Med 6: 395. doi: 10.4172/2161-105X.1000395

Page 3 of 10

were males, 115 were females but in one study with 64 participants the gender of those was not mentioned and also the gender of the controls was not mentioned. The endobronchial lesions under study proved to be malignant in the majority of cases (474/643) but a significant proportion had a benign lesion (168/643) and in one case the lesion remained unidentified. The number of lesions does not match the number of patients in one study, as 318 lesions were detected in 308 patients [16]. All the patients were subjected to Fiberoptic Bronchoscopy (FOB) and imaging of the chest. The main techniques used for the imaging analysis of the chest were axial CT in seven studies [13,14,17,1922] and Virtual Bronchoscopy (VB) in three studies but the results were analyzed only in two of them [17,18,21]. Moreover, some other techniques of the imaging analysis were used, such as low-dose CT [16], super-high resolution CT (SHR-CT) [20], axial maximum intensity projection (MIP) images [15], coronal and sagittal multidetector CT (MDCT) [16], multiplanar reformatting (MPR) [22], volume rendering techniques (VRT) [22] and CT bronchography [14], each used once. The time interval between the performance of FOB and the imaging technique varied between 1 and 105 days, but in 4 of the studies this time interval was not specified. In five of the studies this time was no longer than one month (Table 3). The main inclusion criteria were the suspected or confirmed pulmonary lesion and the high clinical suspicion of lung cancer, but in 3 studies the inclusion criteria were not mentioned. The exclusion criteria were reported only in 4 studies and were mainly referred to end-stage disease or multiple co-morbidities. In all studies the primary target was the detection and description of the endobronchial lesion by the imaging methods in comparison with the endobronchial findings acquired from FOB.

Another issue for the accuracy of the imaging techniques in the detection of a lesion is the size of that lesion. In the studies selected for this review, the size of the lesion was noted only in four, with a range from $1.5 \mathrm{~mm}$ to $140 \mathrm{~mm}$ (Table 4). Moreover, Adali et al. [18] mentioned that $\mathrm{VB}$ detected easier lesions $>50 \mathrm{~mm}$.

\section{Meta-analysis}

The mean number of participants per study was 63.3 (median 36; range 10-308), with a total of 633 subjects. Sensitivity for detection of

\begin{tabular}{|c|c|c|c|c|c|}
\hline & $\begin{array}{c}\text { Recording of the } \\
\text { bronchoscopic findings }\end{array}$ & $\begin{array}{c}\text { Recording of the Imaging } \\
\text { findings }\end{array}$ & $\begin{array}{l}\text { Comparison of the } \\
\text { findings }\end{array}$ & Blinding & Primary endpoint \\
\hline Kim et al. [23] & Yes & Yes & No & No & $\begin{array}{l}\text { Description of the radiological } \\
\text { and broncoscopic features }\end{array}$ \\
\hline Stevic et al. [24] & Yes & Yes & No & No & $\begin{array}{l}\text { Description of the radiological } \\
\text { features }\end{array}$ \\
\hline Sahin et al. [28] & Yes & Yes & No & No & $\begin{array}{l}\text { Description of histological and } \\
\text { radiological correlations }\end{array}$ \\
\hline Olaru et al. [29] & Yes & No & No & No & $\begin{array}{l}\text { Description of histological and } \\
\text { bronchoscopic features }\end{array}$ \\
\hline Laroche et al. [30] & Yes & Yes & No & Yes & $\begin{array}{c}\text { Obtaining an histological } \\
\text { diagnosis }\end{array}$ \\
\hline Sundarakumar et al. [31] & No & No & Yes & No & $\begin{array}{l}\text { Comparison of the diagnostic } \\
\text { accuracy VB/FB }\end{array}$ \\
\hline Kwon et al. [32] & Yes & Yes & Yes & No & $\begin{array}{l}\text { Description of the characteristics } \\
\text { of endobronchial leiomyoma }\end{array}$ \\
\hline Fleiter et al. [33] & No & No & Yes & No & $\begin{array}{l}\text { Detection of endobronchial } \\
\text { stenoses }\end{array}$ \\
\hline
\end{tabular}

Table 2: Characteristics of the studies excluded from the review.

\begin{tabular}{|c|c|c|c|c|c|c|c|}
\hline & Type of study & $\begin{array}{c}\text { Number of } \\
\text { participants }\end{array}$ & Age (years) & Gender & Type of lesion & $\begin{array}{l}\text { Time interval CT- } \\
\text { bronchoscopy }\end{array}$ & Imaging technique \\
\hline Bungay et al. [13] & Prospective & 62 & $\begin{array}{c}70 \\
(49-86)\end{array}$ & $46 \mathrm{~m} / 16 \mathrm{f}$ & Malignant & 3 weeks & Axial CT \\
\hline Ferreti et al. [14] & Retrospective & 28 (+5 cont $)$ & $\begin{array}{c}40 \\
(6-71)\end{array}$ & $18 \mathrm{~m} / 10 \mathrm{f}$ & $\begin{array}{l}24 \text { Benign } \\
4 \text { Malignant }\end{array}$ & 15 days & $\begin{array}{c}\text { Axial CT } \\
\text { CT bronchography }\end{array}$ \\
\hline Lecourtois et al. [15] & Prospective & 10 & $62.2(51-78)$ & $9 \mathrm{~m} / 1 \mathrm{f}$ & Malignant & $1-105$ days & MIP images \\
\hline Westeinde et al. [16] & Prospective & 308 & $\begin{array}{c}61 \\
(50-75)\end{array}$ & $248 \mathrm{~m} / 60 \mathrm{f}$ & Malignant & Not specified & Low dose CT \\
\hline Hoppe et al. [17] & Retrospective & 15 (+5 cont) & $\begin{array}{c}71 \\
(37-88)\end{array}$ & $13 \mathrm{~m} / 2 \mathrm{f}$ & Malignant & 17 days & $\begin{array}{c}\text { Axial CT } \\
\text { Coronal and Sagittal MPR } \\
\text { VB }\end{array}$ \\
\hline Adali et al. [18] & Prospective & 22 & $\begin{array}{c}52 \\
(30-74)\end{array}$ & $16 \mathrm{~m} / 6 \mathrm{f}$ & $\begin{array}{l}14 \text { malignant } \\
7 \text { Benign } \\
1 \text { Unidentified }\end{array}$ & 1 day & $\begin{array}{l}\text { MDCT } \\
\text { VB }\end{array}$ \\
\hline Naidich et al. [19] & Retrospective & 64 (+38 cont) & Not specified & Not specified & $\begin{array}{l}52 \text { Malignant } \\
12 \text { Benign }\end{array}$ & Not specified & Axial CT \\
\hline Aristizabal et al. [20] & Retrospective & 64 & $\begin{array}{c}64 \\
(38-89)\end{array}$ & $60 \mathrm{~m} / 4 \mathrm{f}$ & Malignant & Not specified & Axial CT \\
\hline Finkelstein et al. [21] & Prospective & 44 & $\begin{array}{c}53 \\
(29-88)\end{array}$ & $32 \mathrm{~m} / 12 \mathrm{f}$ & Malignant & 1 Month & $\begin{array}{l}\text { Axial CT } \\
\text { SHR-CT } \\
\quad \text { VB }\end{array}$ \\
\hline Koletsis et al. [22] & Prospective & 16 (+5 cont) & $62.3(19-77)$ & $12 \mathrm{~m} / 4 \mathrm{f}$ & $\begin{array}{l}11 \text { Malignant } \\
5 \text { Benign }\end{array}$ & Not specified & $\begin{array}{l}\text { Axial CT } \\
\text { MPR-VRT } \\
\text { VB }\end{array}$ \\
\hline
\end{tabular}

Table 3: Characteristics of the studies included in the review.Characteristics of the studies included in the review. 
Citation: Kouvela M, Kakavas S, Karetsos C, Balis E (2017) Correlation of the Imaging Findings with Bronchoscopic Findings for the Detection of Endobronchial Lesions: A Systematic Review and Meta-Analysis. J Pulm Respir Med 6: 395. doi: 10.4172/2161-105X.1000395

Page 4 of 10

malignancy in all studies concerning CT ranged from $42.9 \%$ to $95.5 \%$, while sensitivity of VB ranged from $81 \%$ to $90.9 \%$ (Table 4 ). For all other methods, except Axial CT and VB, sensitivity ranged from $81 \%$ to $100 \%$.

Significant between-study heterogeneity was revealed in some tests for specificity or sensitivity, all for CT $\left(\mathrm{Q}=33.3, \mathrm{p}<0.001, \mathrm{I}^{2}=76.0\right.$ for sensitivity and $\mathrm{Q}=28.0, \mathrm{p}<0.001, \mathrm{I}^{2}=71.5$ for specificity), for $\mathrm{VB}$ $\left(\mathrm{Q}=0.73, \mathrm{P}=0.694, \mathrm{I}^{2}=0.0\right.$ for sensitivity and $\mathrm{Q}=29.6, \mathrm{P}<0.001, \mathrm{I}^{2}=93.2$ for specificity), and for OTHER $\left(\mathrm{Q}=9.24, \mathrm{P}=0.100, \mathrm{I}^{2}=45.9\right.$ for sensitivity and $\mathrm{Q}=30.7, \mathrm{P}<0.001, \mathrm{I}^{2}=83.7$ for specificity). Therefore, a fixed effects model was used to calculate the pooled sensitivity and specificity in case of significant between-study heterogeneity, and a random effects model was used in case of non significant between-study heterogeneity (Table 5).

Forest plots of sensitivity and specificity are shown in Figures 1a-1d. Pooled estimates of sensitivity and specificity for axial CT are shown in Table 5. Pooled estimated specificity was similar for CT and other, but pooled estimated sensitivity was higher with other method $(\mathrm{p}<0.05)$. Also, other method had a little higher LR+ and LR-. The AUC of CT and OTHER were similar and equal to 0.90 and 0.92 respectively (Figures 2a-2b).

Significant between-study heterogeneity was revealed in some tests for Negative Predictive Value, for CT $(\mathrm{Q}=72.5, \mathrm{p}<0.001, \mathrm{I} 2=89.0)$, for VB $(\mathrm{Q}=16.9, \mathrm{P}<0.001, \mathrm{I} 2=88.2)$ and for OTHER $(\mathrm{Q}=9.09, \mathrm{P}=0.105$, $\mathrm{I} 2=45.0$ ). Therefore, a fixed effects model was used to calculate the pooled NPV in case of significant between-study heterogeneity, and a random effects model was used in case of non-significant between- study heterogeneity. Forest plots for NPV are shown in Figures 3a-3c. Pooled estimates of NPV for three comparisons are shown in Table 5.

\section{Discussion}

A common problem in clinical practice is high-risk patients presenting with symptoms compatible with lung cancer. The first step in the diagnosis of a suspected lesion is the imaging of the chest. Chest CT scan is a valuable tool which has demonstrated high sensitivity and specificity rates [19]. Over the years, various advanced techniques have been developed aiming to a more detailed assessment of the lungs and chest, using 2-D and 3-D reconstruction algorithms [7]. With these techniques, a clinician can interpret more accurately the information obtained by the axial CT [8]. Although chest CT can offer valuable information for suspected endobronchial lesions, fiberoptic bronchoscopy (FOB) usually represents the first choice diagnostic modality for the accurate diagnosis [10-12].

In this review we collected studies that compared the accuracy of FOB with the chest imaging techniques for the detection and diagnosis of endobronchial lesions. The main focus of this present meta-analysis has been a direct comparison between axial CT and FOB. However, information concerning VB or reformatted CT was considered as relevant, even though limited. This limitation weakens the strength of comparisons between FOB and VB or other $\mathrm{CT}$ imaging techniques, but the data remain interesting. In the included studies, the accuracy of axial CT was analyzed in seven of them (Table 4). Even though the sensitivity of the method was found to be high in most of them reaching a value $95.5 \%$, a different outcome was concluded from Filkenstein et al. who found a sensitivity of only $58.6 \%$, even if the results were interpreted

\begin{tabular}{|c|c|c|c|c|c|c|c|c|}
\hline Study & Imaging & Sensitivity (\%) & $95 \% \mathrm{Cl}$ & Specificity (\%) & $95 \% \mathrm{Cl}$ & NPV & L_CI_NPV & U_CI_NPV \\
\hline Hoppe et al. [17] & $\mathrm{CT}$ & 95.5 & $77.2-99.9$ & 96.1 & $92.1-98.4$ & 99.4 & 96.8 & 99.99 \\
\hline Koletsis et al. [22] & $\mathrm{CT}$ & 95.5 & $77.2-99.9$ & 100 & $47.8-100$ & 83.3 & 35.9 & 99.6 \\
\hline Naidich et al. [19] & CT & 89.8 & $82-95$ & 92.1 & $78.6-98.3$ & 77.78 & 62.91 & 88.8 \\
\hline Aristizabal [20] & CT & 42.9 & $17.7-71.1$ & 89.5 & $66.7-98.7$ & 68 & 46.5 & 85.05 \\
\hline Lecourtois et al. [15] & $\mathrm{CT}$ & 80 & $44.4-97.5$ & 53.3 & $26.6-78.7$ & 80 & 44.4 & 97.5 \\
\hline Westeinde et al. [16] & CT & 81.8 & $48.2-97.7$ & 100 & $98.7-100$ & 99.3 & 97.5 & 99.9 \\
\hline Filkenstein et al. & CT & 58.6 & $38.9-76.5$ & 75 & $34.9-96.8$ & 33.33 & 13.34 & 59.01 \\
\hline Ferreti et al. [14] & $\mathrm{CT}$ & 87.1 & $70.2-96.4$ & 99.5 & 97.3-99.9 & 98.1 & 95.2 & 99.5 \\
\hline Bungay et al. [13] & $\mathrm{CT}$ & 60.6 & $42.1-77.1$ & 86.2 & $68.3-96.1$ & 65.8 & 48.6 & 80.4 \\
\hline Hoppe et al. [17] & VB & 90.9 & $70.8-98.9$ & 98.9 & $96-99.9$ & 98.9 & 96 & 99.9 \\
\hline Adali et al. [18] & VB & 89.5 & $66.9-98.7$ & 33.3 & $1-90.6$ & 33.33 & .84 & 90.57 \\
\hline Filkenstein et al. & VB & 82.9 & $66.4-93.4$ & 45 & $23.1-68.5$ & 60 & 32.29 & 83.66 \\
\hline Hoppe et al. [17] & Sagital reformatted CT & 81 & $58.1-94.6$ & 98.3 & $95.2-99.7$ & 97.78 & 94.41 & 99.39 \\
\hline Koletsis et al. [22] & MPR & 100 & $83.9-100$ & 83.3 & $35.9-99.6$ & 100 & 47.82 & 100 \\
\hline Hoppe et al. [17] & Coronal reformatted $\mathrm{CT}$ & 90.9 & $70.8-98.9$ & 96.6 & $92.8-98.8$ & 98.85 & 95.9 & 99.86 \\
\hline Ferreti et al. [14] & CT and Bronchography & 90.3 & $74.3-97.9$ & 100 & $98.2-100$ & 98.6 & 95.9 & 99.7 \\
\hline Koletsis et al. [22] & VRT & 100 & $83.9-100$ & 62.5 & $24.5-91.5$ & 100 & 47.82 & 100 \\
\hline Filkenstein et al. & SHR-CT & 82.9 & $66.4-93.4$ & 47.4 & $24.5-71.1$ & 60 & 32.29 & 83.66 \\
\hline
\end{tabular}

Table 4: Sensitivity, specificity and NPV for all included studies.

\begin{tabular}{|c|c|c|c|c|c|c|}
\hline & Sensitivity (95\% CI) (\%) & Specificity $(95 \% \mathrm{Cl})(\%)$ & $\mathrm{LR}+(95 \% \mathrm{Cl})$ & LR- $(95 \% \mathrm{CI})$ & DOR (95\% CI) & NPV $(95 \% \mathrm{Cl})$ \\
\hline CT & $79.6(69.7-89.5)$ & $97.4(94.9-99.8)$ & $20.3(4.9-84.1)$ & $0.19(0.10-0.36)$ & $103.0(16.4-650.8)$ & $98.7(97.9-99.6)$ \\
\hline
\end{tabular}

Table 5: Pooled effects of Sensitivity, Specificity and NPV for CT. 
Citation: Kouvela M, Kakavas S, Karetsos C, Balis E (2017) Correlation of the Imaging Findings with Bronchoscopic Findings for the Detection of Endobronchial Lesions: A Systematic Review and Meta-Analysis. J Pulm Respir Med 6: 395. doi: 10.4172/2161-105X.1000395

Study

ID

ES $(95 \% \mathrm{Cl})$

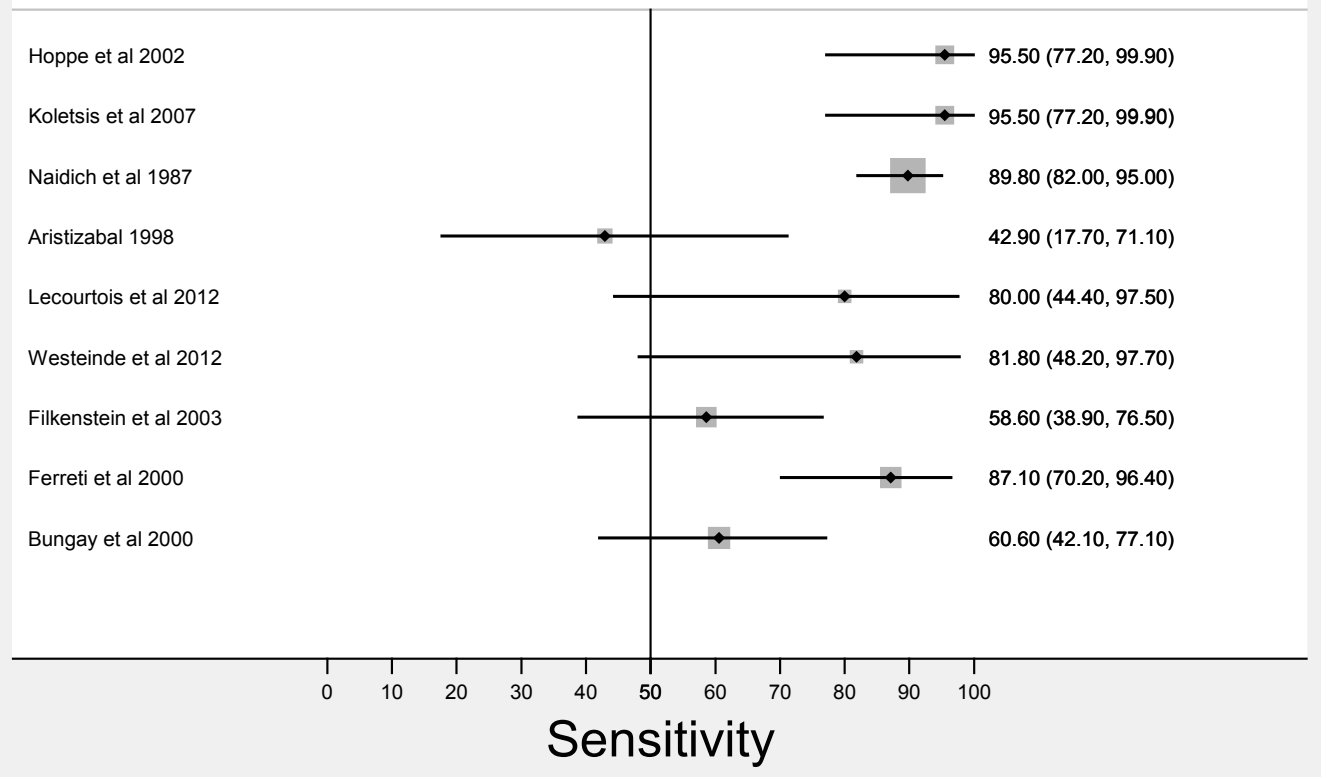

Figure 1a: Forest plot for sensitivity (CT)

Study

ID

ES $(95 \% \mathrm{Cl})$

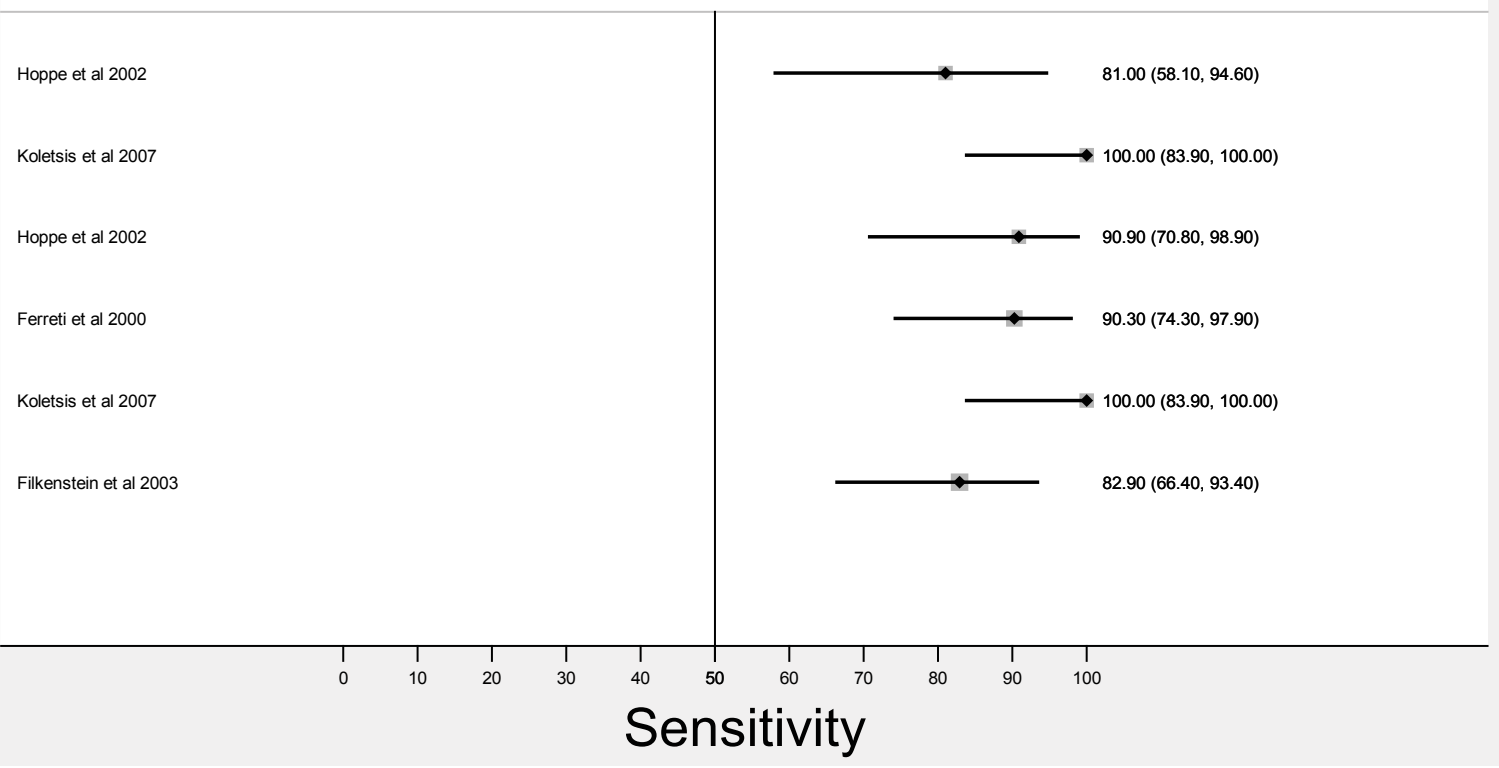

Figure 1b: Forest plot for sensitivity (OTHER).

by terms of number of patients or number of lesions separately. In this study, a large number of endobronchial lesions were not detected in the conventional CT scan (12 lesions form a total number of 29 lesions) but were visible in FOB. This low rate of sensitivity was even lower when it was referred to mucosal or endoluminal masses and was improved for obstructive lesions. At the same time, the results of another CT 
Citation: Kouvela M, Kakavas S, Karetsos C, Balis E (2017) Correlation of the Imaging Findings with Bronchoscopic Findings for the Detection of Endobronchial Lesions: A Systematic Review and Meta-Analysis. J Pulm Respir Med 6: 395. doi: 10.4172/2161-105X.1000395

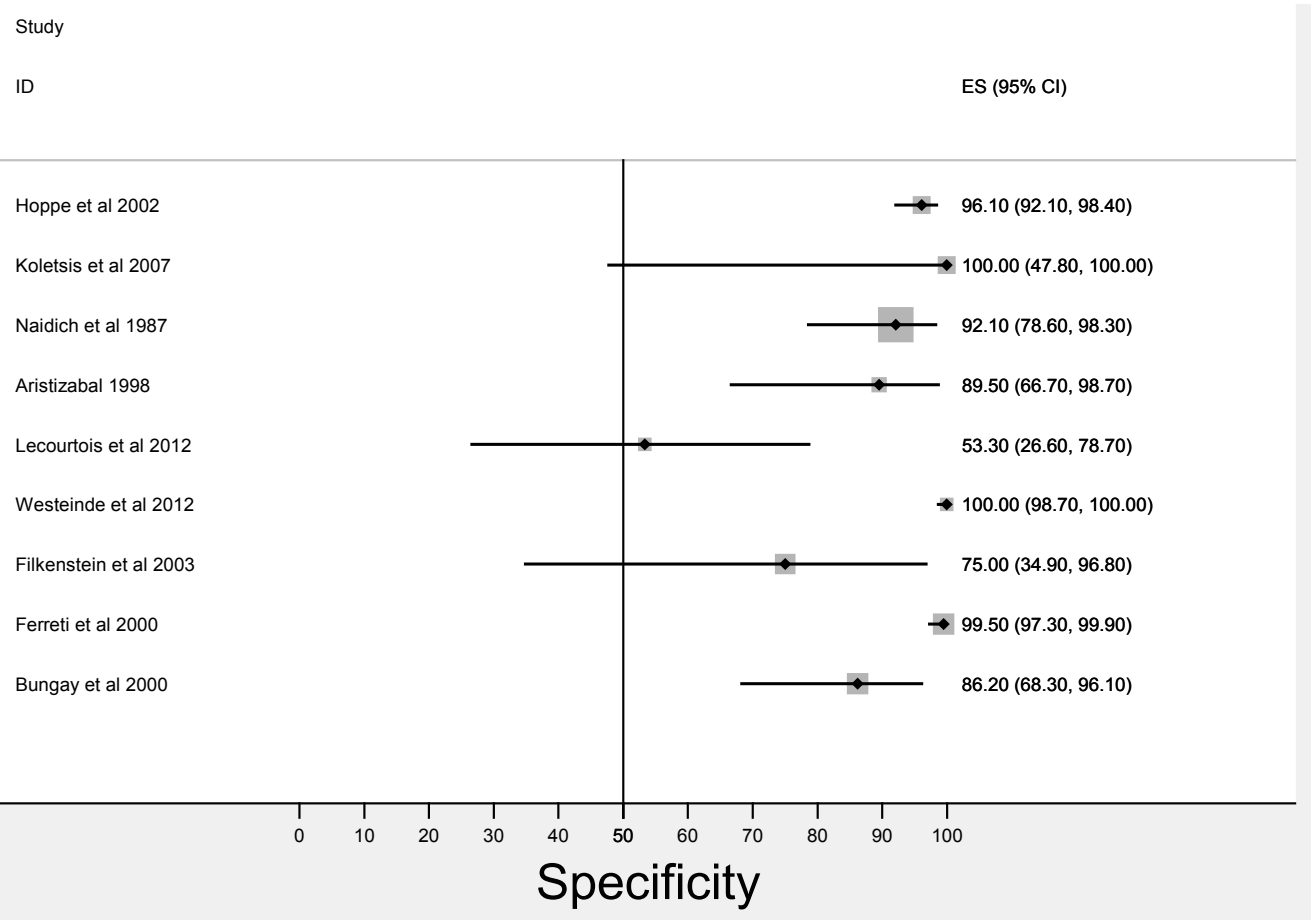

Figure 1c: Forest plot for specificity (CT).

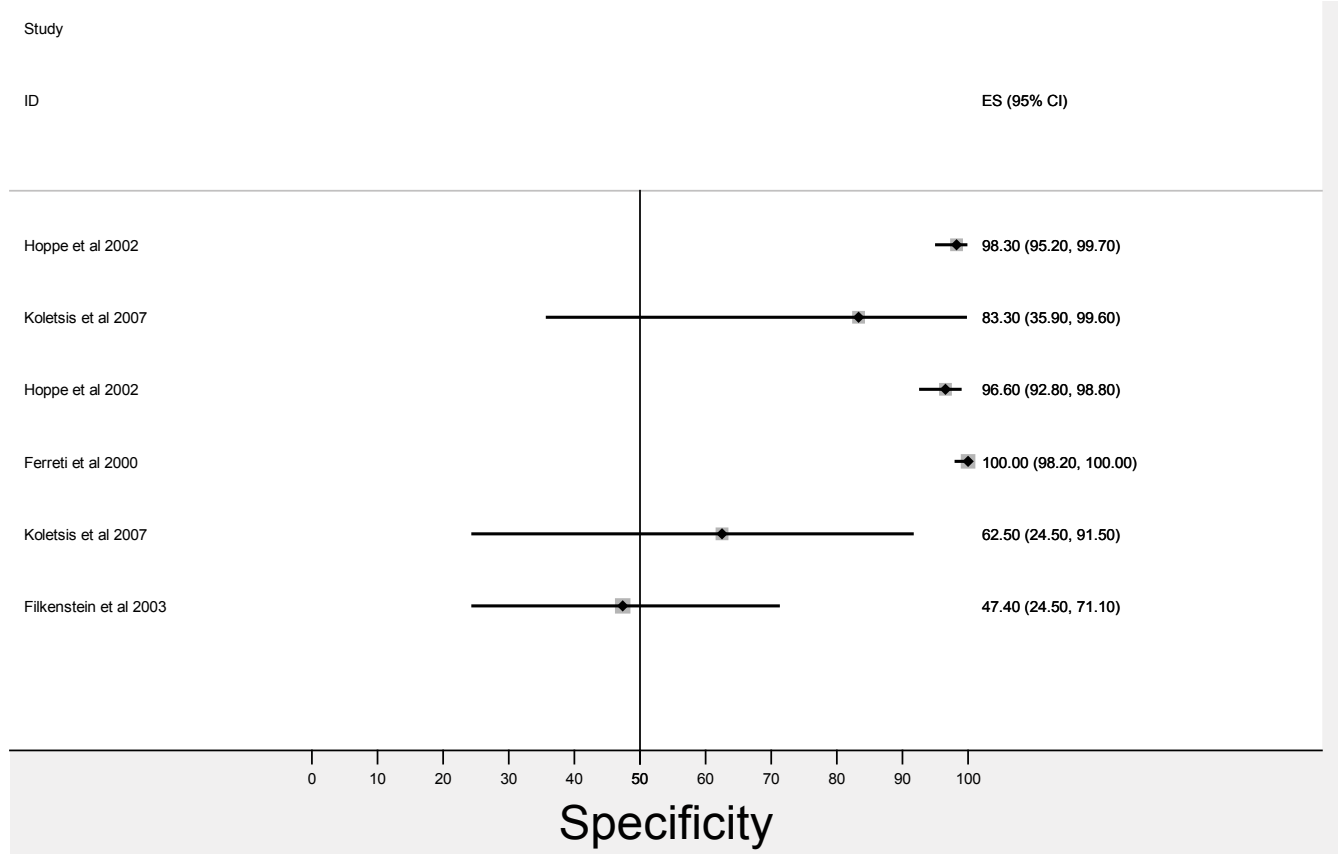

Figure 1d: Forest plot for specificity (OTHER)

technique, Super-High Resolution CT were interpreted, and were found to be superior to those of conventional CT in terms of sensitivity and comparable with those obtained by Virtual Bronchoscopy (VB).

Moreover, in all of the above studies a number of lesions were visualized in the CT scans, but were not detected by FOB. One of the main causes is that FOB has a very low sensitivity rate for peripheral lesions due to the smaller size of the peripheral airways or due to the location of the lesion distal to a high-grade stenosis, which do not allow the bronchoscope to pass through $[9,19]$. Other reasons are the inability of conventional CT to distinguish between an endobronchial lesion and other benign or reversible causes of stenosis, such as mucus 


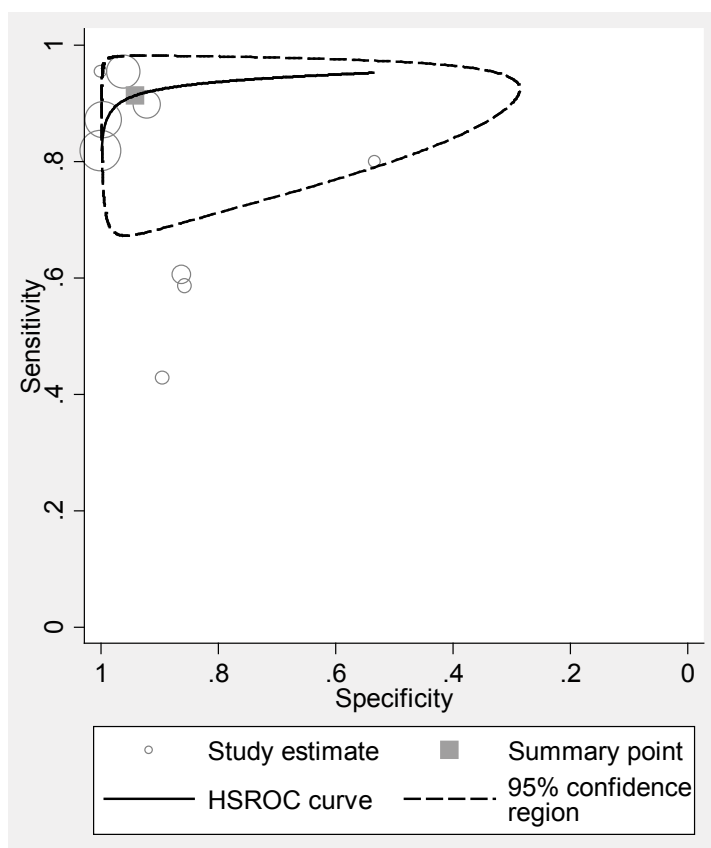

Figure 2a: Summary ROC curves of results from individual studies (CT).



Figure 2b: Summary ROC curves of results from individual studies (OTHER).

plugs, blood or inflammatory edema of the bronchial walls. The results obtained by the study of Aristizabal et al. [20] were inadequate to compare, because the existence of an endobronchial lesion in CT scan was one of the exclusion criteria, so we could only retrieve NPV from the cases of endobronchial lesion that were not detected primary in CT but were discovered later in FOB.

The rest of the studies compared the sensitivity and specificity of several image reconstruction techniques, either with conventional CT or with each other (Tables 4 and 5). Three of the studies have selected
Virtual Bronchoscopy. In the studies of Hoppe and Finkelstein, VB seemed to have higher accuracy than conventional CT. In the work of Adali et al. [18] VB reached a sensitivity of $89.5 \%$ but had a low specificity (33.3\%). This result should be carefully interpreted due to the low number of participants in the study. On the other hand, VB can detect easier than FOB external compressions as it is indicated [18].

The detection of an endobronchial lesion is a problematic issue due to the complicity if the respiratory system and the subjectivity of the methods used for this purpose and this is the reason for the variability of the results. The size of the lesion plays an important role, as the larger is the lesion, the easier is to be detected both radiologicaly and endoscopicaly. Although it should be obvious that in studies in which the lesions were larger, the accuracy of the methods would be greater, the information that we have is not enough to reach this conclusion.

One additional reason for the variability of the results is the subjectivity of the methods used for the detection of the lesion. The interpretation of the imaging results may differ between observers as it is noted [22]. In a study, two observers were used for the interpretation of the CT scan images: one inexperienced pulmonologist and one experienced radiologist. The results of both observers were mentioned separately and even though the difference is not significant between them it is interesting to note that the radiologist felt confident at the same level both with axial CT and the addition of CT bronchography, but the pulmonologist felt more confident for his diagnosis when the more advanced technique was added [22]. In another study, even though both observers were experienced radiologists, there still was variability of the results. Additionally, it is known that bronchoscopy is an operator-depended technique, with greater accuracy and acquisition of histological diagnosis from more experienced bronchoscopists.

According to the existing recommendations, low dose CT is the modality of choice for the detection of lung lesions for the high risk patients. If the Low Dose CT does not reveal any lesion, then the patient is recommended to repeat the CT in 2 years [34]. On the other hand, the results of this review suggest that the negative predictive value of axial $\mathrm{CT}$ is low, and it's overall sensitivity and specificity varies significantly, depending on many factors. This raises the question if low dose CT is enough to exclude lung cancer in high risk patients, or maybe Flexible Bronchoscopy should be performed too, as a general screening tool or in selected cases where the suspicion for lung cancer is high.

Bronchoscopy and computed tomography (CT) are complimentary methods of investigating patients with suspected lung cancer. CT has been shown to be of value prior to bronchoscopy in the investigation of haemoptysis and malignancy. However, the correlation between the detection of endobrochial disease on $\mathrm{CT}$ and direct visualisation at bronchoscopy has not been fully elucidated. Moreover, bronchoscopy is not always available or possible. The utility of CT has been further increased by the development of new techniques and may play an important role in guiding the choice of surgical staging procedures. The increasing use of multidisciplinary medical care requires physicians to have a greater understanding of the abilities and limitations of both bronchoscopy and CT procedures in evaluating endobronchial lesions.

Additionally, newer techniques have been introduced in the field of bronchial endoscopy for the optimal visualization even of the smallest endobronchial lesions (e.g. fluorescence bronchoscopy, high definition (HD) video bronchoscopy) or for the more accurate diagnosis of lesions 
Citation: Kouvela M, Kakavas S, Karetsos C, Balis E (2017) Correlation of the Imaging Findings with Bronchoscopic Findings for the Detection of Endobronchial Lesions: A Systematic Review and Meta-Analysis. J Pulm Respir Med 6: 395. doi: 10.4172/2161-105X.1000395

Study

ID

ES $(95 \% \mathrm{Cl})$

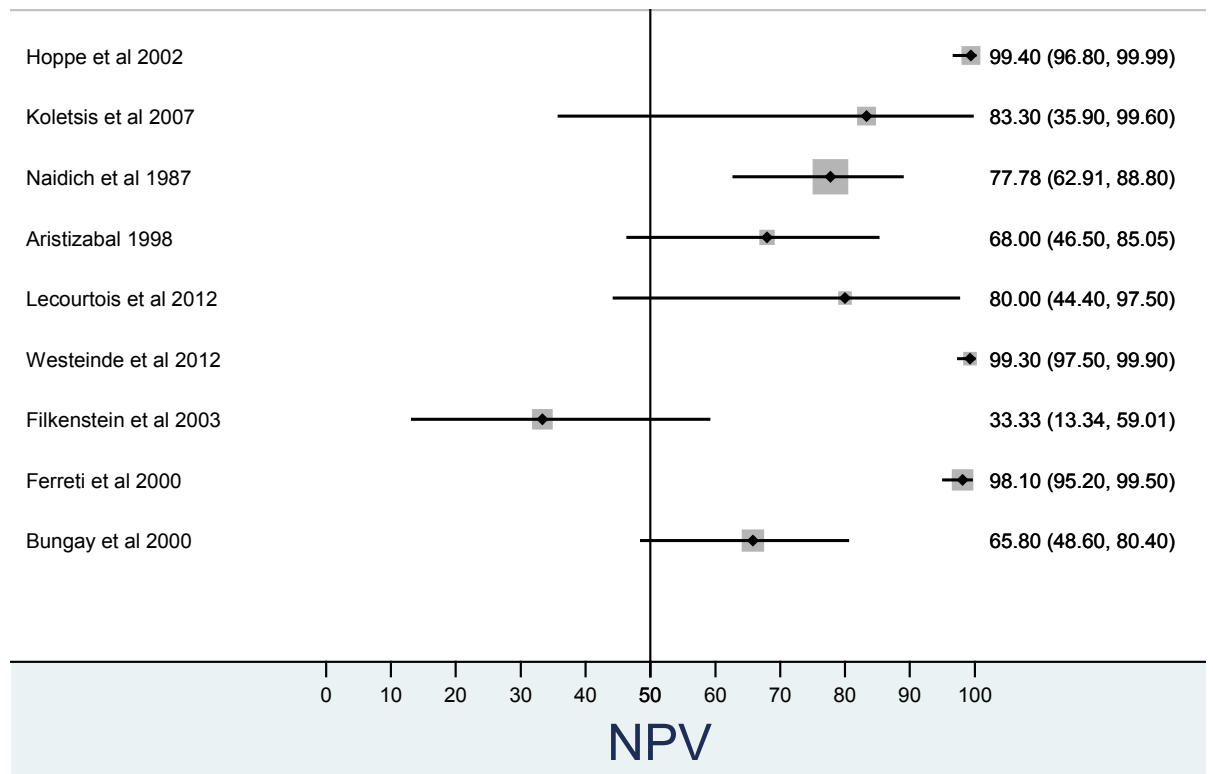

Figure 3a: Forest plot for NPV (CT).

Study

ID

ES $(95 \% \mathrm{Cl})$

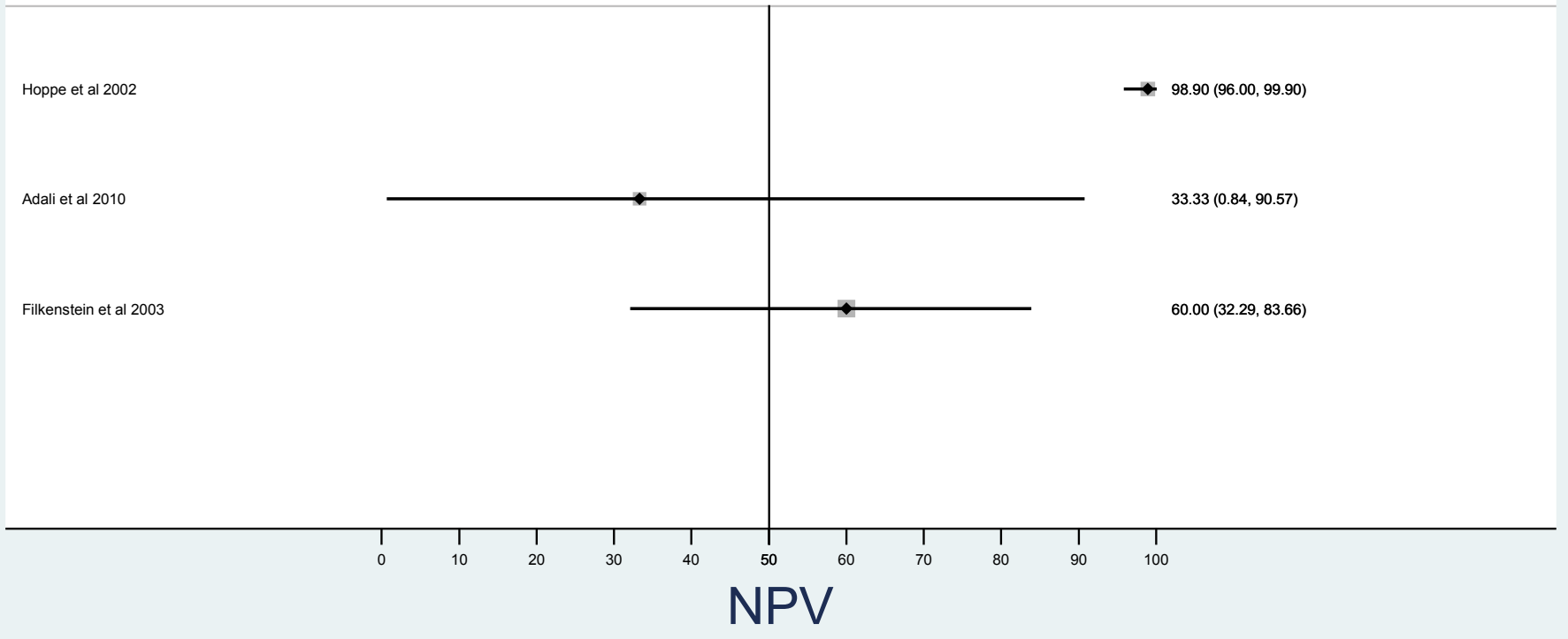

Figure 3b: Forest plot for NPV (VB). 
Citation: Kouvela M, Kakavas S, Karetsos C, Balis E (2017) Correlation of the Imaging Findings with Bronchoscopic Findings for the Detection of Endobronchial Lesions: A Systematic Review and Meta-Analysis. J Pulm Respir Med 6: 395. doi: 10.4172/2161-105X.1000395

Study

ID

ES $(95 \% \mathrm{Cl})$

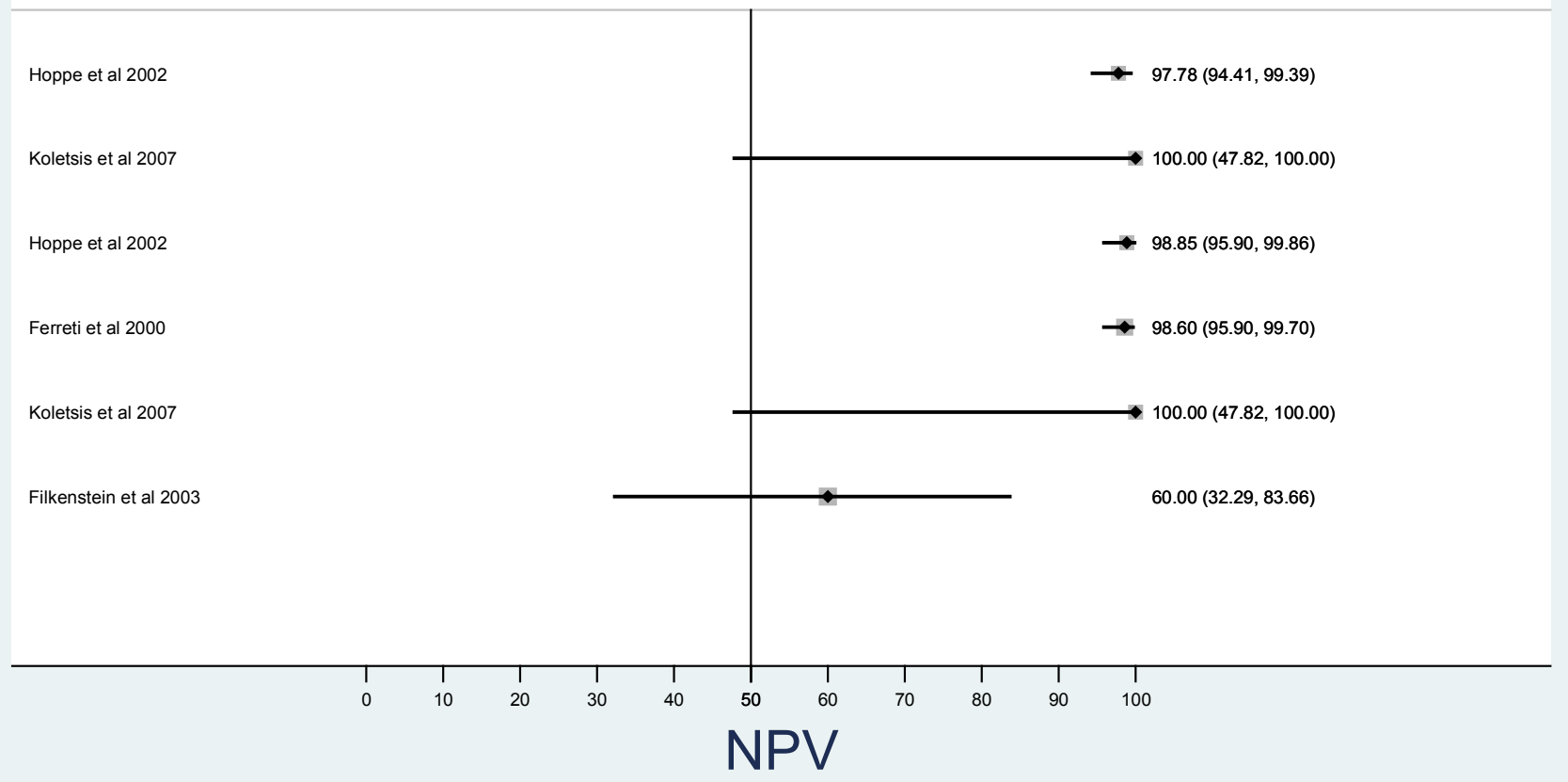

Figure 3c: Forest plot for NPV (OTHER).

that are not easily detected endobronchialy (e.g. EBUS bronchoscopy). Further investigation needs to be conducted on the adding value of those techniques, in comparison with the existing imaging techniques for the timely and effective diagnosis of lung cancer.

\section{Limitations}

The quality of the selected studies was the most important limitation in this review. In the study of Aristizabal et al. [20] the existence of an endobronchial lesion in CT scan was among the exclusion criteria, and so we could retrieve only the NPV of CT scans for endobronchial lesions. Additionally, in most of the studies the number of participants was small, with more than half of them to include less than 50 patients each. Also, in some cases important information failed to be demonstrated, such as the size of the lesions, the technical details of the methods used or the time interval between the imaging and the FOB.

\section{Conclusions}

Fiberoptic Bronchoscopy remains the "gold standard" for the detection, the characterization and the diagnosis of endobronchial lesions, but imaging techniques are useful and safe methods for screening, staging, follow-up and pre-operative preparation of the patient. Even though axial CT retains a high sensitivity and specificity for the detection of endobronchial lesions, the negative predictive value remains low. Newer imaging reconstruction techniques can offer even greater accuracy with higher negative predictive value.

\section{References}

1. Siegel RL, Miller KD, Jemal A (2015) Cancer statistics. CA Cancer J Clin 65: $5-29$.
2. Alberg AJ, Brock MV, Ford JG, Samet JM, Spivack SD (2013) Epidemiology of lung cancer: Diagnosis and management of lung cancer, 3rd ed: American College of Chest Physicians evidence-based clinical practice guidelines. Chest 143: e1S-e29S.

3. Youlden DR, Cramb SM, Baade PD (2008) The International Epidemiology of Lung Cancer: geographical distribution and secular trends. J Thorac Oncol 3: 819-831.

4. Revel MP, Carette MF, Torrent M, Trédaniel J (2014) Diagnosis and standardized report for non-small cell lung cancer. Diagn Interv Imaging 95: 727-738.

5. Munden RF, Swisher SS, Stevens CW, Stewart DJ (2005) Imaging of the patient with non-small cell lung cancer. Radiology 237: 803-818.

6. Naidich DP, Harkin TJ (1995) Airways and lung: correlation of CT with fiberoptic bronchoscopy. Radiology 197: 1-12.

7. Nair A, Godoy MC, Holden EL, Madden BP, Chua F, et al. (2012) Multidetector CT and postprocessing in planning and assisting in minimally invasive bronchoscopic airway interventions. Radiographics 32: E201-E232.

8. Boiselle PM, Reynolds KF, Ernst A (2002) Multiplanar and three-dimensiona imaging of the central airways with multidetector CT. AJR Am J Roentgenol 179: $301-308$.

9. Rivera MP, Mehta AC, Wahidi MM (2013) Establishing the diagnosis of lung cancer: Diagnosis and management of lung cancer, 3rd ed: American College of Chest Physicians evidence-based clinical practice guidelines. CHEST 143: e142S-e165S.

10. Traill ZC, Gleeson FV (2003) Bronchoscopy and surgical staging procedures and their correlation with imaging. Eur J Radiol 45: 39-48.

11. Haga T, Fukuoka M, Morita M, Cho K, Tatsumi K (2014) Indications and complications associated with fiberoptic bronchoscopy in very elderly adults. $J$ Am Geriatr Soc 62: 1803-1805.

12. Hsu LH, Liu CC, Ko JS, Chen CC, Feng AC (2014) Safety of interventional bronchoscopy through complication review at a cancer center. Clin Respir J. 
Citation: Kouvela M, Kakavas S, Karetsos C, Balis E (2017) Correlation of the Imaging Findings with Bronchoscopic Findings for the Detection of Endobronchial Lesions: A Systematic Review and Meta-Analysis. J Pulm Respir Med 6: 395. doi: 10.4172/2161-105X.1000395

Page 10 of 10

13. Bungay HK, Pal CR, Davies CW, Davies RJ, Gleeson FV (2000) An evaluation of computed tomography as an aid to diagnosis in patients undergoing bronchoscopy for suspected bronchial carcinoma. Clin Radiol 55: 554-560.

14. Ferretti GR, Thony F, Bosson JL, Pison C, Arbib F, et al. (2000) Benign abnormalities and carcinoid tumors of the central airways: diagnostic impact of CT bronchography. AJR Am J Roentgenol 174: 1307-1313.

15. Lecourtois B, Jankowski A, Arbib F, Lantuejoul S, Brichon PY, et al. (2012) Endobronchial tumours in a campaign for early detection of bronchial cancer: Computed tomography versus endoscopy. Diagn Interv Imaging 93: 604-611.

16. van 't Westeinde SC, Horeweg N, Vernhout RM, Groen HJ, Lammers JW, et al. (2012) The Role of Conventional Bronchoscopy in the Workup of Suspicious CT Scan Screen-Detected Pulmonary Nodules. Chest 142: 377-84.

17. Hoppe H, Walder B, Sonnenschein M, Vock P, Dinkel HP (2002) Multidetector CT virtual bronchoscopy to grade tracheobronchial stenosis. AJR Am J Roentgenol 178: 1195-1200.

18. Adali F, Uysal A, Bayramoglu S, Guner NT, Yilmaz G, et al. (2010) Virtual and fiber-optic bronchoscopy in patients with indication for tracheobronchial evaluation. Ann Thorac Med 5: 104-109.

19. Naidich DP, Lee JJ, Garay SM, McCauley DI, Aranda CP, et al. (1987) Comparison of CT and fiberoptic bronchoscopy in the evaluation of bronchial disease. AJR Am J Roentgenol 148: 1-7.

20. Aristizabal JF, Young KR, Nath H (1998) Can chest CT decrease the use of preoperative bronchoscopy in the evaluation of suspected bronchogenic carcinoma? Chest 113: 1244-1249.

21. Finkelstein SE, Schrump DS, Nguyen DM, Hewitt SM, Kunst TF, et al. (2003) Comparative evaluation of super high-resolution CT scan and virtual bronchoscopy for the detection of tracheobronchial malignancies. Chest 124 : 1834-1840.

22. Koletsis EN, Kalogeropoulou C, Prodromaki E, Kagadis GC, Katsanos K, et al. (2007) Tumoral and non-tumoral trachea stenoses: evaluation with threedimensional CT and virtual bronchoscopy. J Cardiothorac Surg 12: 18.

23. Kim SA, Um SW, Song JU, Jeon K, Koh WJ, et al. (2010) Bronchoscopic features and bronchoscopic intervention for endobronchial hamartoma. Respirology 15: 150-154.
24. Whiting P, Rutjes AW, Reitsma JB, Bossuyt PM, Kleijnen J (2003) The development of QUADAS: a tool for the quality assessment of studies of diagnostic accuracy included in systematic reviews. BMC Med Res Methodol 10: 25

25. Whiting PF, Rutjes AW, Westwood ME, Mallett S, Deeks JJ, et al. (2011) QUADAS-2: a revised tool for the quality assessment of diagnostic accuracy studies. Ann Intern Med 155: 529-536.

26. Higgins JP, Thompson SG, Deeks JJ, Altman DG (2003) Measuring inconsistency in meta-analyses. BMJ 327: 557-560.

27. Stevic R, Milenkovic B, Stojsic J, Pesut D, Ercegovac M, et al. (2012) Clinical and radiological manifestations of primary tracheobronchial tumours: a single centre experience. Ann Acad Med 41: 205-211.

28. Sahin F, Yildiz P (2011) Radiological, Bronchoscopic and Histopathologic Characteristics of Patients with Primary Lung Cancer in Turkey (2006-2009). Asian Pac J Cancer Prev 12: 1947-1952.

29. Olaru M, MÄfı̈̈fescu D, Demetrian A, loncicÄ $f$ L, StÄfnoiu B, et al. (2013) A combined imagistic and morphological approach of lung tumors: study on 64 cases. Rom J Morphol Embryol 54: 1067-1074.

30. Laroche C, Fairbairn I, Moss H, Pepke-Zaba J, Sharples L, et al. (2000) Role of computed tomographic scanning of the thorax prior to bronchoscopy in the investigation of suspected lung cancer. Thorax 55: 359-363.

31. Sundarakumar DK, Bhalla AS, Sharma R, Hari S, Guleria R, et al. (2011) Multidetector CT evaluation of central airways stenoses: Comparison of virtual bronchoscopy, minimal-intensity projection, and multiplanar reformatted images. Indian J Radiol Imaging 21: 191-194.

32. Kwon YS, Kim H, Koh WJ, Suh GY, Chung MP, et al. (2008) Clinical characteristics and ef?cacy of bronchoscopic intervention for tracheobronchial leiomyoma. Respirology 13: 908-912.

33. Fleiter T, Merkle EM, Aschoff AJ, Lang G, Stein M, et al. (1997) Comparison of real-time virtual and fiberoptic bronchoscopy in patients with bronchial carcinoma: opportunities and limitations. AJR Am J Roentgenol 169: 15911595.

34. National Comprehensive Cancer Network (2016) Clinical Practice Guidelines in Oncology, Lung Cancer Screening, Version 1. 